\title{
B7-H3 Overexpression Predicts Poor Survival of Cancer Patients: A Meta- Analysis
}

\author{
Zhimeng Ye $\mathrm{e}^{\mathrm{a}}$ Zhuojun Zheng ${ }^{\mathrm{b}}$ Xiaodong $\mathrm{Li}^{\mathrm{c}}$ Yuandong Zhu ${ }^{\mathrm{b}}$ Zhaoping Zhong ${ }^{\mathrm{a}}$ \\ Linrui Penga Yanyan Wu ${ }^{d}$
}

aDepartment of Orthopedics, The Sixth Hospital of Ningbo, Ningbo, bepartment of Hematology, The Third Affiliated Hospital of Soochow University, Changzhou, 'Department of Oncology, The Third Affiliated Hospital of Soochow University, Changzhou, dDepartment of Stomatology, Yinzhou Hospital Affiliated to Medical School of Ningbo University, Ningbo, China

\section{Key Words}

B7-H3 • Prognosis • Cancer • Meta-analysis

\begin{abstract}
Background: $\mathrm{B} 7-\mathrm{H} 3$ exhibits altered expression in various cancers. However, the correlation between $\mathrm{B} 7-\mathrm{H} 3$ expression and prognosis of cancer patients remains controversial. Therefore, we elicit a meta-analysis to investigate the potential value of $\mathrm{B} 7-\mathrm{H} 3$ in the prognostic prediction in human cancers. Materials and Methods: We searched PubMed (last update by June 15th, 2016) to identify studies assessing the effect of B7-H3 on survival of cancer patients. Hazard ratios (HRs) for overall survival (OS), recurrence free survival (RFS) and progression-free survival (PFS) from individual studies were calculated and pooled by using a random-effect or fix-effect model, and heterogeneity and publication bias analyses were also performed. Results: Data from 24 observational studies consisting of 4141 patients were summarized. An elevated baseline B7-H3 was significantly correlated with poor OS (pooled HR $=2.09 ; 95 \%$ $\mathrm{CI}=1.60-2.74 ; P<0.001)$. Differences across subgroups of tumor type $(P=0.324)$, year of publication $(P=0.431)$, ethnicity $(P=0.940)$, source of HR $(P=0.145)$, analysis type $(P=0.178)$ and sample size $(P=0.909)$ were not significant. Furthermore, high $\mathrm{B} 7-\mathrm{H} 3$ expression also predicted a significantly poor RFS (pooled HR $=1.39 ; 95 \% \mathrm{CI}=1.11-1.75 ; P=0.004$ ) but not PFS. Conclusions: This meta-analysis clarifies that elevated B7-H3 expression is significantly associated with poor survival in cancer patients.

\section{Introduction}

The B7 family proteins presented on antigen-presenting cells where they are recognized by costimulatory receptors on $\mathrm{T}$ cells are important in T-cell proliferation, tolerance, and

Z. Ye, Z. Zheng and X. Li are the co-first authors.

Yanyan Wu

KARGER 


\section{Cellular Physiology Cell Physiol Biochem 2016;39:1568-1580

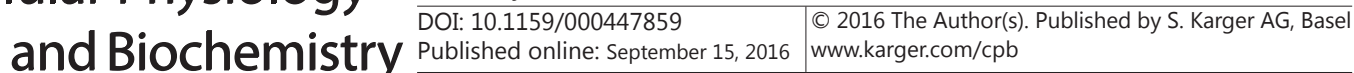 \\ Ye et al.: B7-H3 and Cancer Survival}

activation [1]. These proteins can be divided into three groups, according to the signals they transduce during T cell activation: I) co-stimulatory (e.g. B7-1 and B7-2); II) inhibitory (e.g. B7-H1); and III) co-stimulatory/inhibitory (e.g. B7-H3 and B7-H4) [2].

B7-H3 is a type I transmembrane protein that shares $20 \% \sim 27 \%$ amino acid identity with other B7 family members [3]. The murine B7-H3 consists of a single extracellular variabletype IgV-IgC domain and a signature intracellular domain (2 Ig B7-H3), and the human B7-H3 possesses an additional isoform, 4Ig B7-H3, which contains a nearly exact tandem duplication of the IgV-IgC domain [4]. The receptor of B7-H3 still remains unknown, thus the role of B7-H3 in adaptive immune responses still remains elusive [5]. B7-H3 is expressed on tumor cells such as carcinomas of the colon, ovary, prostate, pancreas, kidney, prostate and urothelial carcinoma [6-10], but is not expressed, or expressed at low levels, in most normal cells or tissues $[5,11]$. The exact function of B7-H3 remains unknown while both stimulatory and inhibitory effects on T-cell immunity have been identified [12]. The tumor cells expressed B7-H3 are also suggested to be correlated with the biological behaviors of cancer cells, such as migration, invasion, and metastatic capacity, and finally contributed to cancer progression $[6-9,13,14]$. B7-H3 overexpression has been observed to be associated with poor clinical outcome in some cancers $[6,8,10]$. However, studies investigating associations of B7-H3 expression with survival have shown conflicting results [5].

However, there has not been any pooled analysis on B7-H3 predicting the prognosis of cancer patients so far. Thus, a meta-analysis was conducted, including studies that assessing the role of B7-H3 in the clinical outcome of patients with various cancers to date.

\section{Materials and Methods}

\section{Literature search strategy}

The meta-analysis was performed following the Meta analysis of Observational Studies in Epidemiology group (MOOSE)[15]. A computerized search of MEDLINE was performed via PubMed from January 1990 to June 2016 to identify studies using the following search criteria: "B7-H3 OR CD276 OR B7H3" (all fields) AND "prognostic OR prognosis OR prognostication OR survive OR survived OR survival" (all fields) AND "tumor OR tumour OR neoplasm OR cancer OR carcinoma OR leukemia OR myeloma OR lymphoma" (all fields). Searches were limited to human articles published in the English or Chinese. Two investigators (Z. Ye and $\mathrm{Y} . \mathrm{Wu}$ ) inspected the title and abstracts of citations and obtained the full texts. The last search date was 15 th June 2016.

\section{Inclusion and exclusion criteria}

Studies were eligible if they met the following initial inclusion criteria: (a) the expression of B7-H3 in tumor tissue or serum; (b) correlated survival outcomes with B7-H3 expression (Table 1) and provided sufficient data to estimate the hazard ratio (HR) and 95\% confidence interval (CI); (c) clearly described B7-H3 detection; (d) clearly defined cut-off values. Studies were excluded if they were (a) review articles, case reports, experimental studies, conference abstracts, animal studies or letters; (b) unpublished data; (c) lacked essential data for the pooled calculation. Two reviewers independently evaluated titles and abstracts of the identified articles and subsequently excluded those that were irrelevant.

\section{Data extraction}

Eligible articles were reviewed independently by two authors (Y. Zhu and X. Li). Disagreements were resolved by consensus and consultation with a third investigator. Data were extracted independently by two authors (Z. Ye and Z. Zheng) using a standard protocol. The required information was collected: first author; year of publication; country of study belongs; number of patients; gender; tumor type; tumor stage; follow-up period; method of quantifying B7-H3 expression; definition of B7-H3 cut-off value to dichotomize patients into high and low groups; quality of study and HR for survival outcome, as well as their $95 \% \mathrm{CI}$ and $P$ values. Multivariate Cox analysis was priority of inclusion if available. Otherwise, univariate hazard analysis or Kaplan-Meier survival curves were conducted instead [16]. Parts of HRs were calculated using the graphical data. Rounding was avoided when performing these calculations. 


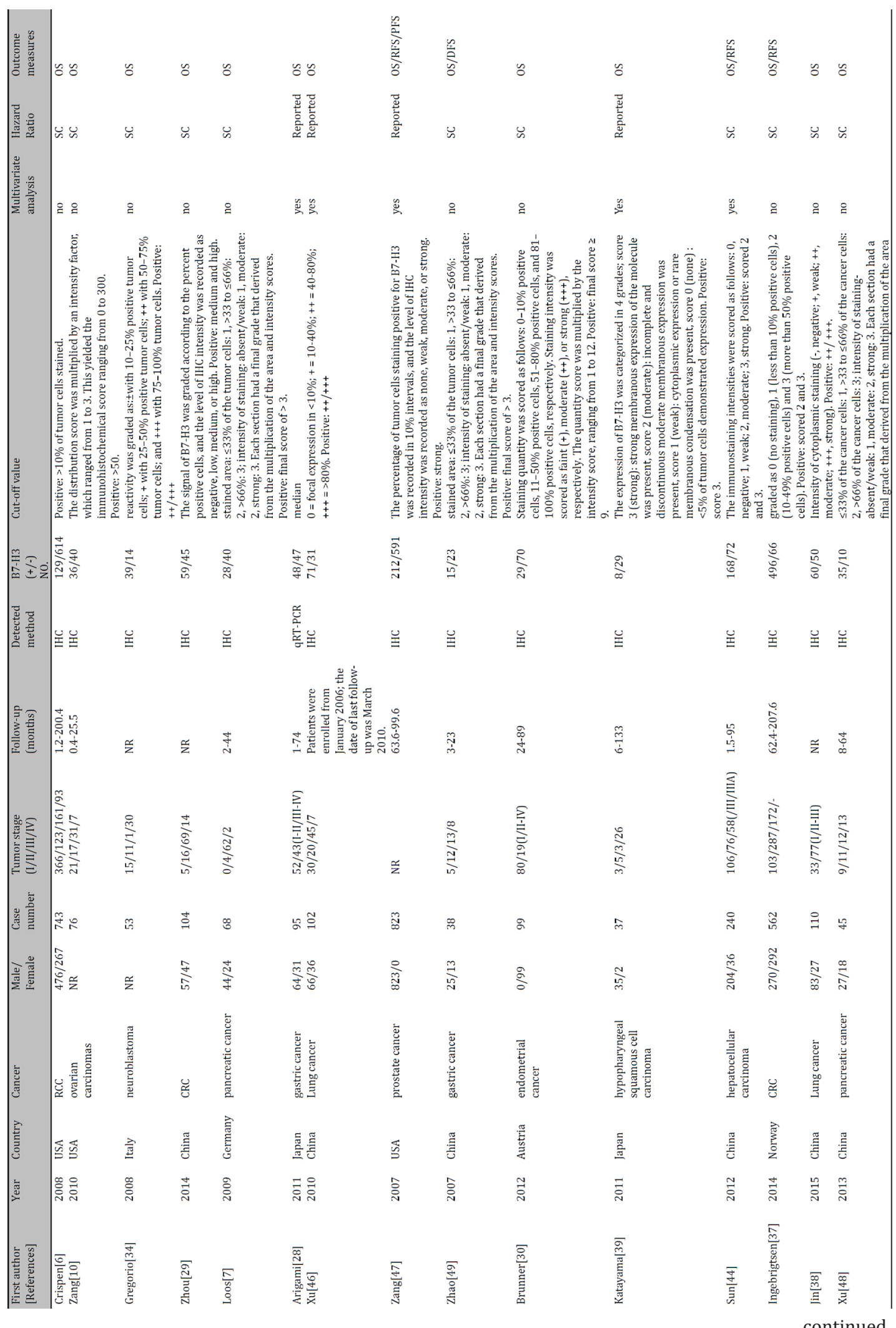

Table 1. Main characteristics of all studies included in the meta-analysis. RCC, renal cell carcinoma; CRC, Colorectal cancer; IHC, immunohistochemistry; SC, survival curve; NR, not report; OS, overall survival; RFS, recurrence free survival; DFS, disease free survival; PFS, progression-free survival 
Quality assessment

The quality of each study was evaluated independently by two authors according to the NewcastleOttawa Quality Assess-ment Scale (NOS) [17]. For quality assessment, scores ranged from 0 to 9 ( 9 as best), and studies with scores of 6 or more were rated as high quality. The studies with at least scores of 4 were included and subsequent pooled analysis. None of the studies adhered in full to the REMARK (REporting recommendations for tumor MARKer prognostic studies) criteria for reporting studies on clinically prognostic tumor markers [18].

\section{Statistical analysis}

Meta-analysis was carried out using the STATA version 12.0 (Stata Corporation, College Station, TX, USA). Cut-off values of B7-H3 provided in the articles dichotomize patients into high and low groups. HRs and $95 \% \mathrm{Cls}$ were combined to assess the effective value of $\mathrm{B} 7-\mathrm{H} 3$ expression on survival outcome. We extracted statistical variables directly if they were described in the study. The data from Kaplan-Meier survival curves were read by 2 independent researchers using Engauge Digitizer version 4.1. We also asked the corresponding authors of eligible articles for needed additional information and original data. HR greater than 1 indicated worse prognosis in patients and HR less than 1 suggested a better prognosis based on B7-H3 expression. Inter-study heterogeneity was assessed by visual inspection of forest plots, by performing the Chi-square test (assessing the $P$ value), and by calculating the $I^{2}$ statistic $[19,20]$. A random-effects model (the DerSimonian-Laird method) was used when heterogeneity present $(P<0.05$ and/or $\left.I^{2}>50 \%\right)$. Or the fixed-effects model (Mante-Haenszel method) was applied.

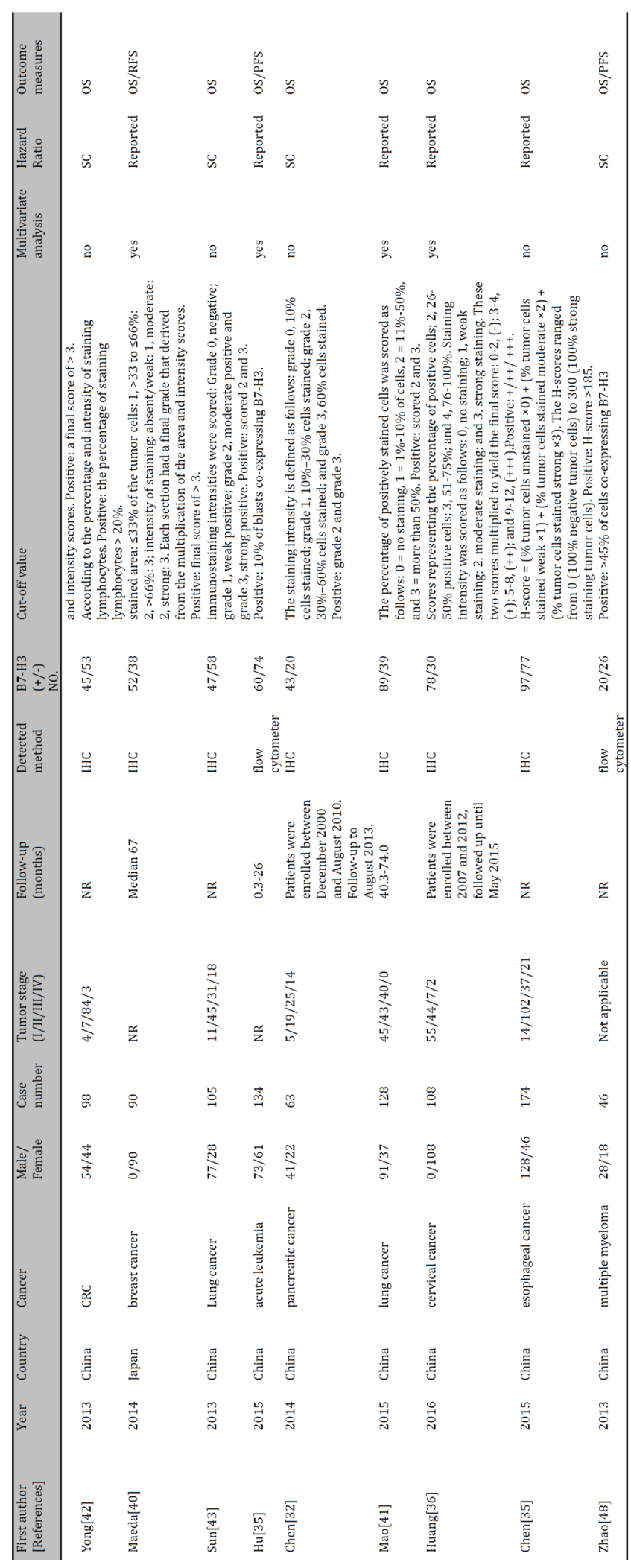

Publication bias assessment

Funnel plots with Egger's bias indicator test were used for assessing publication bias [21]. Scatterplots demonstrated each study's effect in relation to their sample size, and skewed indicate that bias exists. Pooled 
data of at least 3 studies (recommend more than 10) are required to calculate Egger's regression intercept. When publication bias was identified, sensitivity analysis was performed to assess the potential impact of missing studies. A two-tailed $P$ value $<0.05$ was considered statistically significant.

\section{Results}

Excluded and included studies

A total of 100 articles for consideration were yielded by using the described searching strategy. Title, publication types and abstract assessment identified 30 manuscripts appropriate for investigation of the correlation between B7-H3 expression and patient survival in various malignant

Fig. 1. Flow chart of the search strategy and selected studies. tumors. Among these, 6 articles were excluded [22-27] because of lacking some important data or unable to extract data (Fig. 1). Finally, 24 studies fulfilled the criteria for metaanalysis[7, 10, 28-49].

\section{Study characteristics}

The included studies analyzed a total of 4141 patients from P. R. China, USA, Italy, Germany, Austria, Japan and Norway. Details regarding the characteristics of the included studies are listed in Table 1 . Patients from several regions were diagnosed with a variety of cancers, including renal cell carcinoma, colorectal cancer, ovarian carcinomas, neuroblastoma, pancreatic cancer, gastric cancer, lung cancer, prostate cancer, endometrial cancer, hypopharyngeal squamous cell carcinoma, hepatocellular carcinoma, breast cancer, hematological malignancies, cervical cancer, and esophageal cancer. The majority of studies (70.8\%) reported on Asians, and 7 (29.2\%) on Caucasians. Thirteen studies (54.2\%) were published in 2013 or later. HRs were reported directly in 9 studies and estimated indirectly in the others. The cut-off values varied in these studies. The endpoints overall survival (OS) was addressed in all studies, while recurrences free survival (RFS) and progression-free survival (PFS) were addressed in 4 studies, respectively.

\section{Quality assessment}

Each of the 24 eligible studies included in our meta-analysis was assessed for quality according to NOS. The quality of all studies included varied from 4 to 9 , with a mean of 5.7. A higher value indicated better methodology. Therefore, all studies were included in the subsequent analysis.

\section{Meta-analysis results}

Overall Survival. All included studies provided suitable data for OS analysis. The main results of this meta-analysis are listed_in Table 2. Significant inter-study heterogeneity was found $\left(I^{2}=78.9 \%, P<0.001\right)$, we applied the random-effects model to pool the HRs. The statistical results showed that B7-H3 upregulation was significantly associated with poor OS according to pooled analysis with a combined HR $2.09(95 \% \mathrm{CI}=1.60-2.74 ; P<0.001)$ (Fig. 2). Considering the inter-study heterogeneity, the significance of B7-H3 expression was further evaluated via subgroup analysis based on the tumor type, ethnicity, source of 
Ye et al.: B7-H3 and Cancer Survival

Table 2. Pooled hazard ratios for overall survival according to subgroup analysis. CRC, Colorectal cancer; HR, hazard ratio; OS, overall survival

\begin{tabular}{|c|c|c|c|c|c|c|}
\hline Outcome subgroup & No. of patients & No. of studies & Effects model & HR $(95 \% \mathrm{CI})$ Figure & $P$ value & $\begin{array}{c}\text { Heterogeneity } \\
\text { (Higgins } I^{2} \text { statistic) }\end{array}$ \\
\hline OS & 4141 & 24 & Random & $2.09(1.60,2.74)$ & $Z=5.38, P<0.001$ & $P<0.001 ; I^{2} 78.9 \%$ \\
\hline \multicolumn{7}{|l|}{ Tumor type } \\
\hline $\mathrm{CRC}$ & 764 & 3 & Fix & $1.21(0.82,1.79)$ & $Z=0.96, P=0.336$ & $P=0.235 ; I^{2} 30.9 \%$ \\
\hline Pancreatic & 176 & 3 & Random & $1.37(0.51,3.64)$ & $Z=0.63, P=0.530$ & $P=0.001 ; I^{2} 85.5 \%$ \\
\hline Gastric & 133 & 2 & Random & $0.66(0.08,5.23)$ & $Z=0.40, P=0.692$ & $P=0.034 ; I^{2} 77.7 \%$ \\
\hline Lung & 445 & 4 & Random & $2.68(1.55,4.64)$ & $Z=3.53, P<0.001$ & $P=0.030 ; I^{2} 66.4 \%$ \\
\hline Hematological & 180 & 2 & Fix & $2.13(1.39,3.27)$ & $Z=3.46, P=0.001$ & $P=0.983 ; I^{2} 0 \%$ \\
\hline other & 2443 & 10 & Random & $2.86(1.89,4.31)$ & $Z=5.00, P<0.001$ & $P<0.001 ; I^{2} 75.4 \%$ \\
\hline \multicolumn{7}{|l|}{ Ethnicity } \\
\hline Asian & 1717 & 17 & Random & $2.09(1.60,2.74)$ & $Z=6.08, P<0.001$ & $P=0.020 ; I^{2} 46.1 \%$ \\
\hline Caucasian & 2424 & 7 & Random & $2.11(1.07,4.18)$ & $Z=2.14, P=0.032$ & $P<0.001 ; I^{2} 92.4 \%$ \\
\hline \multicolumn{7}{|l|}{ HR obtain } \\
\hline Reported in text & 1691 & 9 & Random & $2.66(1.80,3.92)$ & $Z=4.92, P<0.001$ & $P=0.018 ; I^{2} 56.8 \%$ \\
\hline Survival curve extrapolated & 2450 & 15 & Random & $1.80(1.26,2.57)$ & $Z=3.24, P=0.001$ & $P<0.001 ; I^{2} 84.4 \%$ \\
\hline \multicolumn{7}{|l|}{ Analysis type } \\
\hline Multivariate & 1480 & 8 & Random & $2.80(1.81,4.34)$ & $Z=4.61, P<0.001$ & $P=0.049 ; I^{2} 52.5 \%$ \\
\hline Univariate & 2661 & 16 & Random & $1.86(1.34,2.58)$ & $Z=3.73, P<0.001$ & $P<0.001 ; I^{2} 83.0 \%$ \\
\hline \multicolumn{7}{|l|}{ Sample size } \\
\hline$>200$ & 2368 & 4 & Random & $2.05(0.94,4.47)$ & $Z=1.81, P=0.070$ & $P<0.001 ; I^{2} 94.8 \%$ \\
\hline$<200$ & 1773 & 22 & Random & $2.07(1.59,2.70)$ & $Z=5.37, P<0.001$ & $P<0.001 ; I^{2} 63.1 \%$ \\
\hline
\end{tabular}

Fig. 2. Forest plots of studies evaluating hazard ratios of elevated B7-H3 expression in cancer patients for overall survival.

\begin{tabular}{|c|c|c|c|}
\hline \multirow{2}{*}{\multicolumn{2}{|c|}{$\begin{array}{l}\text { Study } \\
\text { ID }\end{array}$}} & \multicolumn{2}{|r|}{$\%$} \\
\hline & & $\mathrm{HR}(95 \% \mathrm{CI})$ & Weight \\
\hline Crispen2008 & $\leftarrow$ & $4.08(3.15,5.30)$ & 5.91 \\
\hline Zang2010 & $\rightarrow$ & $2.05(1.15,3.72)$ & 4.82 \\
\hline Gregorio2008 & & $5.10(1.96,13.25)$ & 3.49 \\
\hline Zhou2014 & & $1.75(0.71,4.30)$ & 3.68 \\
\hline Loos2009 & & $0.54(0.31,0.95)$ & 4.92 \\
\hline Arigami2011 & $\rightarrow$ & $1.56(1.01,2.54)$ & 5.28 \\
\hline Xu2010 & & $9.26(3.28,26.32)$ & 3.23 \\
\hline Zang2007 & & $3.48(1.50,8.09)$ & 3.87 \\
\hline Zhao2007 & & $0.18(0.02,0.98)$ & 1.46 \\
\hline Brunner2012 & & $3.07(1.20,7.87)$ & 3.54 \\
\hline Katayama2011 & & $9.80(1.86,55.56)$ & 1.79 \\
\hline Sun2012 & 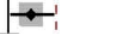 & $1.42(1.03,2.04)$ & 5.68 \\
\hline Ingebriglsen2014 & & $0.98(0.73,1.31)$ & 5.82 \\
\hline $\operatorname{Jin} 2015$ & $\rightarrow$ & $1.65(1.03,2.66)$ & 5.23 \\
\hline Xu2013 & $\longrightarrow$ & $3.55(1.35,9.36)$ & 3.45 \\
\hline Yong2013 & $\rightarrow$ & $1.64(0.82,3.28)$ & 4.42 \\
\hline Maeda2014 & & $3.12(0.53,18.27)$ & 1.69 \\
\hline Sun2013 & $\stackrel{1}{\rightarrow+\infty}$ & $2.59(1.47,4.57)$ & 4.89 \\
\hline Hu2015 & $\longrightarrow$ & $2.14(1.24,3.68)$ & 4.98 \\
\hline Chen2014 & $\rightarrow+1$ & $1.59(0.96,2.63)$ & 5.13 \\
\hline Mao2015 & $\longrightarrow$ & $2.26(1.21,4.23)$ & 4.67 \\
\hline Huang2016 & +1 & $6.57(1.51,28.53)$ & 2.18 \\
\hline Chen2015 & $\rightarrow-1$ & $1.56(1.04,2.35)$ & 5.47 \\
\hline Zhao2013 & $\longrightarrow$ & $2.12(0.78,3.14)$ & 4.41 \\
\hline Overall $(\mathrm{I}-$ squared $=78.9 \%, \mathrm{p}=0.000$ ) & $\diamond$ & $2.09(1.60,2.74)$ & 100.00 \\
\hline \multicolumn{4}{|c|}{ NOTE: Weights are from random effects analysis } \\
\hline .018 & 1 & 6 & \\
\hline
\end{tabular}

$\mathrm{HR}$, analysis type and sample size. Elevated B7-H3 as a negative predictor on OS was only confirmed in patients with lung cancer (pooled HR $=2.68 ; 95 \% \mathrm{CI}=1.55-4.64 ; P<0.001$ ), hematological malignancies (pooled $\mathrm{HR}=2.13 ; 95 \% \mathrm{CI}=1.39-3.27 ; P=0.001$ ), and other cancers (pooled HR $=2.86 ; 95 \% \mathrm{CI}=1.89-4.31 ; P<0.001$ ), but not in patients with colorectal cancer, gastric cancer and pancreatic cancer (Fig. 3). Significant inter-study heterogeneity remained in lung cancer and other cancer subgroups $\left(I^{2}=66.4 \%, P=0.03\right.$ and $I^{2}=75.4 \%, P<$ 0.001 ). Elevated B7-H3 expression was associated with poor OS in Asian (pooled HR =2.09; $95 \% \mathrm{CI}=1.60-2.74 ; P<0.001$ ) and Caucasian populations (pooled $\mathrm{HR}=2.11 ; 95 \% \mathrm{CI}=1.07$ 4.18; $P=0.032)$. Significant heterogeneity could be observed in subgroups $\left(I^{2}=46.1 \%, P=\right.$ 0.02 and $\left.I^{2}=92.4 \%, P<0.001\right)$. The similar results were demonstrated in other subgroups of HR reported directly in articles (pooled HR $=2.66 ; 95 \% \mathrm{CI}=1.80-3.92 ; P<0.001$ ), HR estimated indirectly by survival curve extrapolated (pooled $\mathrm{HR}=1.80 ; 95 \% \mathrm{CI}=1.26-2.57 ; P$ 
Fig. 3. Forest plot of the relationship between elevated B7-H3 expression and overall survival in patients with a variety of cancers.

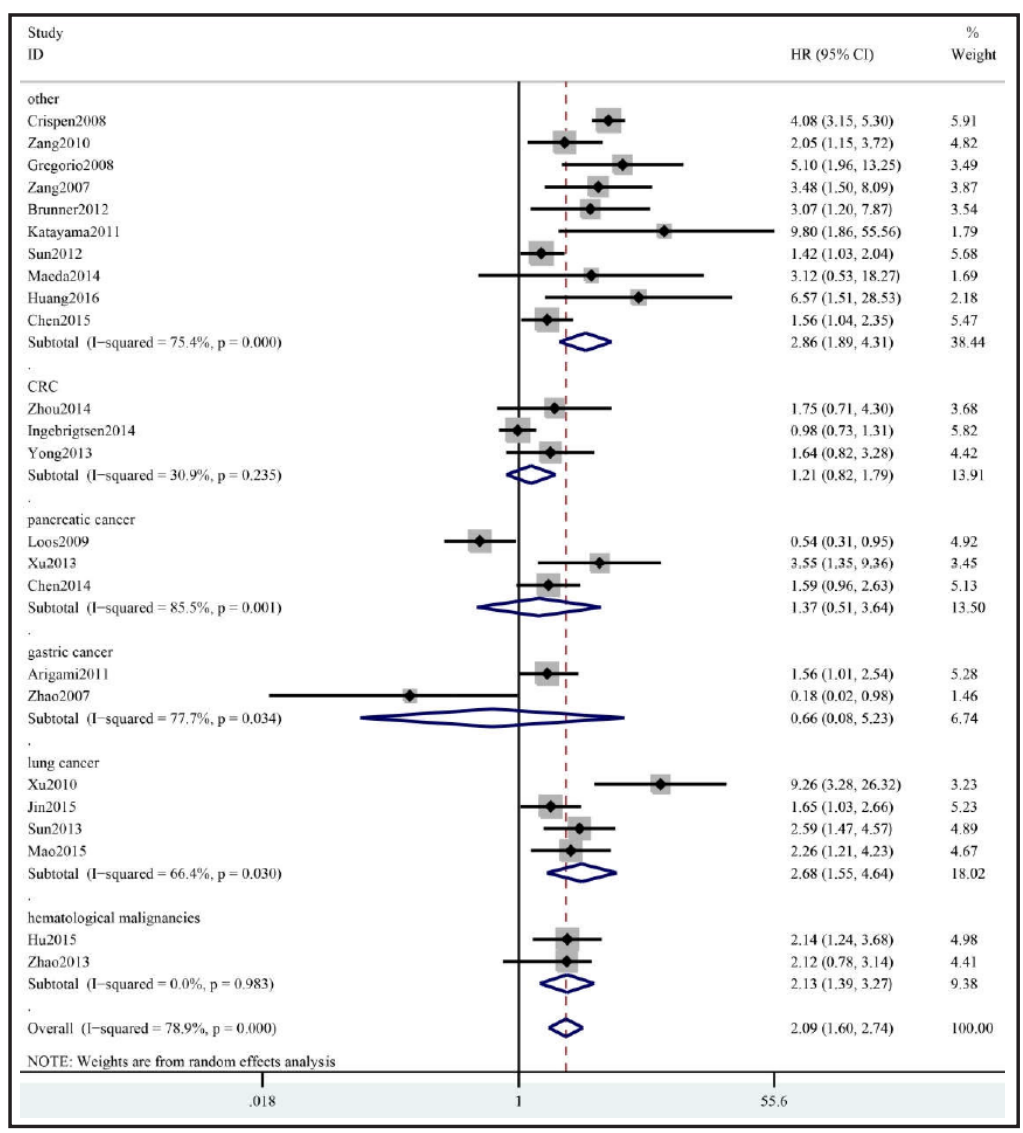

Fig. 4. Sensitivity analysis for meta-analysis of B7-H3 expression.

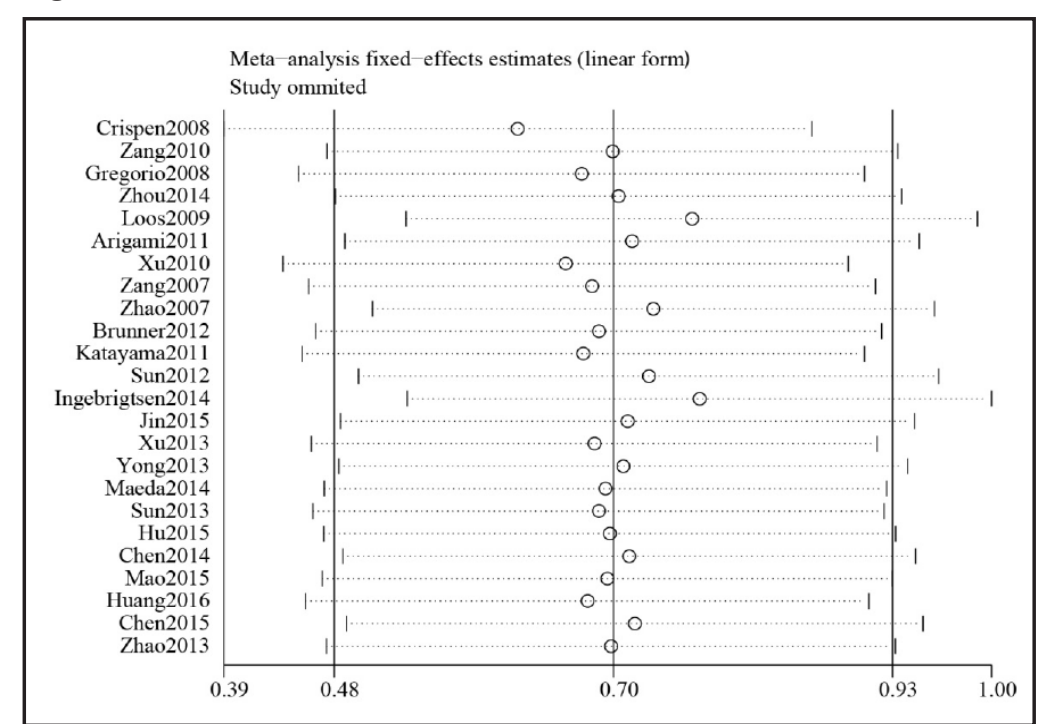

$=0.001$ ), multivariate analysis (pooled $\mathrm{HR}=2.80 ; 95 \% \mathrm{CI}=1.81-4.34 ; P<0.001$ ), univariate analysis (pooled HR =1.86; 95\% CI = 1.34-2.58; $P<0.001$ ) and sample size $<200$ (pooled HR $=2.07 ; 95 \%$ CI $=1.59-2.70 ; P<0.001)$. Significant inter-study heterogeneity was detected in all such subgroups.

Heterogeneity analysis. Sensitivity analysis was performed by sequential omission of individual studies using the fixed-effects model, and the result pattern was not obviously impacted by any single study (Fig. 4). A meta-regression to explore the potential factors responsible for the heterogeneity was conducted. None of factors including tumor type $(\mathrm{P}=$ 
Fig. 5. Funnel plots of publication biases on the relationships between B7$\mathrm{H} 3$ expression and overall survival in cancer patients.

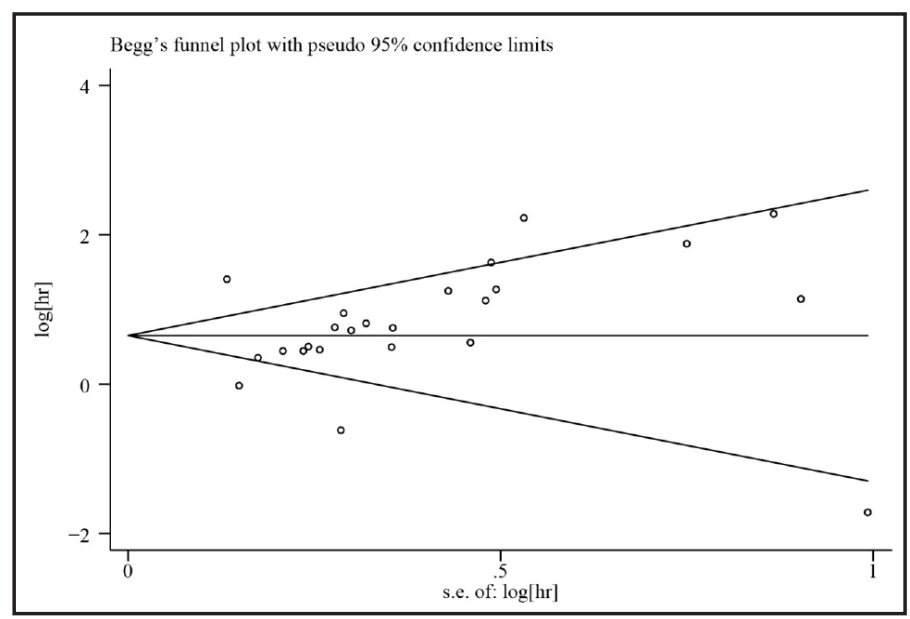

Fig. 6. Forest plots of studies evaluating hazard ratios of elevated B7-H3 expression in various cancers for recurrence free survival.

\begin{tabular}{|c|c|c|c|}
\hline $\begin{array}{l}\text { Study } \\
\text { ID }\end{array}$ & & $\mathrm{HR}(95 \% \mathrm{Cl})$ & $\begin{array}{c}\% \\
\text { Weight }\end{array}$ \\
\hline Zang2007 & & $1.39(1.01,1.92)$ & 49.95 \\
\hline Sun2012 & $\rightarrow$ & $1.54(1.00,2.38)$ & 27.41 \\
\hline Ingebrigtsen2014 & $\Leftrightarrow$ & $1.04(0.61,1.67)$ & 20.32 \\
\hline Maeda2014 & $i$ & $5.47(1.23,24.27)$ & 2.32 \\
\hline Overall (I- squared $=36.6 \%, p=0.193$ ) & & $1.39(1.11,1.75)$ & 100.00 \\
\hline .0412 & & 4.3 & \\
\hline
\end{tabular}

Fig. 7. Forest plots of studies evaluating hazard ratios of elevated B7-H3 expression in various cancers for progression-free survival.

\begin{tabular}{|c|c|c|}
\hline $\begin{array}{l}\text { Study } \\
\text { ID }\end{array}$ & $\mathrm{HR}(95 \% \mathrm{Cl})$ & $\begin{array}{c}\% \\
\text { Weigh }\end{array}$ \\
\hline Zang2007 & $2.79(1.74,4.46)$ & 28.12 \\
\hline Zhao2007 & $0.22(0.11,0.95)$ & 20.14 \\
\hline Hu2015 & $1.95(1.08,3.51)$ & 26.70 \\
\hline Zhao2013 & $2.01(0.71,2.98)$ & 25.03 \\
\hline Overall (I-squared $=83.3 \%, \mathrm{p}=0.000$ ) & $1.40(0.62,3.17)$ & 100.00 \\
\hline NOTE: Weights are from random effects analysis & & \\
\hline 11 & 9.09 & \\
\hline
\end{tabular}

0.324), year of publication ( $P=0.431)$, ethnicity $(P=0.940)$, source of $H R(P=0.145)$, analysis type $(\mathrm{P}=0.178)$ and sample size $(\mathrm{P}=0.909)$ took responsibility for the heterogeneity. It revealed that heterogeneity was created under the action of various factors. 


\begin{tabular}{|c|c|}
\hline Cellular Physiology & Cell Physiol Biochem 2016;39:1568-1580 \\
\hline diphominte & \begin{tabular}{l|l} 
DOI: 10.1159/000447859 & 2016 The Author(s). Published by S. Karger AG, Basel \\
Published online: September 15, 2016 & ww.karger.com/cpb
\end{tabular} \\
\hline
\end{tabular}

Table 3. Pooled hazard ratios for progression-free survival according to subgroup analysis. HR, hazard ratio; PFS, progression-free survival

\begin{tabular}{lcccccc}
\hline Outcome subgroup & No, of patients & No. of studies & Effects model & HR $(95 \%$ Cl) Figure & $P$ value & Heterogeneity (Higgins $I^{2}$ statistic) \\
\hline PFS & 1041 & 4 & Random & $1.40(0.62,3.17)$ & $Z=0.81, P=0.419$ & $P<0.001 ; I^{2} 83.3 \%$ \\
$\begin{array}{l}\text { Analysis type } \\
\text { Multivariate }\end{array}$ & 957 & 2 & Fix & $2.43(1.68,3.51)$ & $Z=4.72, P<0.001$ & $P=0.352 ; I^{2} 0 \%$ \\
$\quad \begin{array}{l}\text { Univariate } \\
\text { Tumor type }\end{array}$ & 84 & 2 & Random & $0.69(0.08,6.03)$ & $Z=0.33, P=0.419$ & $P=0.001 ; I^{2} 91.1 \%$ \\
$\quad$ prostate cancer & 823 & 1 & - & $2.79(1.74,4.46)$ & $Z=4.27, P<0.001$ & - \\
$\quad$ Gastric & 38 & 1 & - & $0.22(0.11,0.95)$ & $Z=2.75, P=0.006$ & - \\
Hematological & 180 & 2 & Fix & $1.97(1.25,3.11)$ & $Z=2.93, P=0.003$ & $P=0.949 ; I^{2} 0 \%$ \\
\hline
\end{tabular}

\section{Publication bias}

The publication bias of all enrolled studies was evaluated using funnel plots, and Egger's and Begg's tests. The funnel plots were nearly symmetric by visual inspection as shown in Fig. 5, which revealed no evidence of publication bias. The conclusion was confirmed by Egger's tests $(P=0.442)$. Hence, publication bias was not presented in this meta-analysis.

Recurrences free survival and progression-free survival

Four studies comprising a total of 1715 patients provided suitable data for RFS analysis. No significant inter-study heterogeneity was detected $\left(I^{2}=36.6 \% ; P=0.193\right)$ and fixed-effects model was applied. It revealed that high expression of B7-H3 was statistically significant associated with poor RFS (pooled $\mathrm{HR}=1.39 ; 95 \% \mathrm{CI}=1.11-1.75 ; P=0.004$ ). A forest plot of study-specific HRs for RFS is shown in Fig. 6.

Another 4 studies pooled for PFS analysis which comprising a total of 1041 patients. Significant inter-study heterogeneity was found $\left(I^{2}=83.3 \%, P<0.001\right)$. However, expression of B7-H3 was not statistically significant associated with PFS (pooled HR $=1.40 ; 95 \% \mathrm{CI}=$ $0.62-3.17 ; P=0.419$ ). All the HRs and corresponding 95\% CIs are shown in Table 3 . The forest plot is shown in Fig. 7. Subgroup analysis showed elevated B7-H3 only associated with poor PFS in multivariate analysis $(\mathrm{HR}=2.43 ; 95 \% \mathrm{CI}=1.68-3.51 ; P<0.001)$ with no heterogeneity among studies $\left(I^{2}=0 \%\right.$; $\left.P=0.352\right)$. Subgroup analysis by tumor type indicated that adverse effect of elevated B7-H3 on PFS was in patients with prostate cancer (HR = 2.79; 95\% CI = 1.74-4.46; $P<0.001$ ), while favorable effect of elevated B7-H3 on PFS was in patients with gastric cancer $(\mathrm{HR}=0.22 ; 95 \% \mathrm{CI}=0.11-0.95 ; P=0.006)$.

\section{Discussion}

The prognostic value of B7-H3 expression remained inconclusive [5]. In this study, we performed a pooled analysis to explore the prognostic role of B7-H3 in 4141 patients with various cancers from 24 studies. To the best of our knowledge, there have not been any other meta-analyses evaluating the correlation between B7-H3 expression and clinical outcomes of cancer patients.

The pooled risk of elevated B7-H3 for OS in cancers was significant with a combined HR of 2.09 (95\% CI 1.60-2.74, $P<0.001)$, which confirmed that B7-H3 was correlated with poor OS and might act as an independent risk factor. However, Zhao et al. [49] and Loos et al. [5] found the opposite conclusions. Both of them had very small sample sizes (38 for Zhao et al. and 68 for Loos et al.). Moreover, Loos et al. [7] only collected data of post-operation cases and they analyzed OS after operation. So their inconsistency is possibly due to the bias of sample selection and relatively small sample size. In the subgroup analysis, the B7-H3 showed the inconsistent prognostic effects in different tumor types. Elevated B7-H3 expression was correlated with poor OS in lung cancer, hematological malignancy and other cancer, but was not in colorectal cancer, pancreatic cancer or gastric cancer. The similar phenomenon was observed in subgroup analysis based on sample size as elevated B7-H3 in studies with $<200$ patients accompanied with poor OS, while it was not statistically significant in studies with 


\section{Cellular Physiology Cell Physiol Biochem 2016;39:1568-1580 \\ \begin{tabular}{cc|c|c|c|} 
DOI: 10.1159/000447859 & $\begin{array}{l}\text { O 2016 The Author(s). Published by S. Karger AG, Basel } \\
\text { wwww.karger.com/cpb }\end{array}$
\end{tabular} \\ Ye et al.: B7-H3 and Cancer Survival}

$>200$ patients. It seemed to suggest that the obvious heterogeneity among these 24 studies may chiefly induced by tumor type or sample size. But further meta-regression analysis disputed this conclusion. It revealed that heterogeneity was created under the action of various factors rather than single one. Besides, this meta-analysis also indicated that cancer patients with elevated B7-H3 have a significantly poor RFS but not PFS. But in subgroup of multivariate analysis, B7-H3 was found to be correlated with poor PFS. The more reliable result than univariate analysis suggested that B7-H3 could still be a negative factor for predicting PFS, which was similar to OS and RFS.

As detected by immunochemistry technique, over $60 \%$ and up to $93 \%$ of tumor tissues display aberrant expression of B7-H3 in the majority of cancer types [50]. Overexpression of B7-H3 has been associated with multiple cancers including esophageal cancer [41], pancreatic cancer [26], cervical cancer [36], non-small-cell lung cancer [38] and colorectal cancer [37]. However, high B7-H3 expression is also reported to be associated with better survival in acute myeloid leukemia [23]. This may be due to the different features of various cancers as well as the differences of sample sizes or measurement. In general, the conclusions from other researchers are consistent with ours.

As members of B7 family, higher B7-H1 expression in human cancer tissues of [51] renal cell carcinoma [52] ovarian cancer [53] non-small cell lung cancer [41], esophageal cancer [54], malignant pleural mesothelioma [55] and colorectal carcinoma [56] is significantly correlated with poor prognosis, while in breast cancer [57], non-small cell lung cancer [58], ovarian cancer [59], renal cell carcinoma [60], pancreatic cancer [26], oral squamous cell carcinoma [61], cholangiocarcinoma [62], hepatocellular carcinoma [63] and esophageal squamous cell carcinoma [64], aberrant expression of B7-H4 has been demonstrated to be associated with a poor clinical outcome. Therefore, we conclude that B7 family members play similar role as negative prognostic factors in tumor development.

Some limitations still exist and details need to be refined. Confined eligible studies resulted in relatively insufficiency data in the subgroup analyses, especially for RFS and PFS. Lack of a unified cut-off value in B7-H3 expression caused various cut-off values in eligible studies. The inaccurate cut-off values may affect the efficiency of B7-H3 as a prognostic biomarker. Most studies measured B7-H3 by immunohistochemistry, studies of hematological malignancy used flow cytometer because surface markers of mononuclear cells were more accurate than myeloid tissue. Identification of the most appropriate cut-off values are to be further explored. Several HRs were calculated from the data extracted from the survival curves, which inevitably caused small statistical errors. Finally, multivariate analyses may be more optimal to estimate effect size than univariate analyses only reported in few studies. Though pooled HRs based on univariate analyses does not show a notable difference in this study, it is possibly to overestimate the effect size in univariate analyses.

\section{Conclusions}

This meta-analysis clarifies that high B7-H3 expression was significantly associated with poor OS and RFS in cancer patients and can substantially improve prognosis prediction. Further prospective multi-center studies designed adequately with larger sample size are needed to confirm the prognosis value of B7-H3 in cancer patients, as well as to explore more effective therapy strategies.

\section{Disclosure Statement}

The authors declare that they have no conflicts of interest concerning this article. 


\section{Cellular Physiology Cell Physiol Biochem 2016;39:1568-1580 and Biochemistry Published online: September 15, 2016 \begin{tabular}{l|l} 
DOI: 10.1159/000447859 2016 The Author(s). Published by S. Karger AG, Basel \\
www.karger.com/cpb
\end{tabular} \\ Ye et al.: B7-H3 and Cancer Survival}

\section{References}

1 Hansen JD, Du Pasquier L, Lefranc MP, Lopez V, Benmansour A, Boudinot P: The B7 family of immunoregulatory receptors: a comparative and evolutionary perspective. Mol Immunol 2009;46:457472.

2 Zang X, Allison JP: The B7 family and cancer therapy: costimulation and coinhibition. Clin Cancer Res 2007;13:5271-5279.

3 Chapoval AI, Ni J, Lau JS, Wilcox RA, Flies DB, Liu D, Dong H, Sica GL, Zhu G, Tamada K, Chen L: B7-H3: a costimulatory molecule for T cell activation and IFN-gamma production. Nat Immunol 2001;2:269-274.

4 Steinberger P, Majdic O, Derdak SV, Pfistershammer K, Kirchberger S, Klauser C, Zlabinger G, Pickl WF, Stockl J, Knapp W: Molecular characterization of human 4Ig-B7-H3, a member of the B7 family with four Ig-like domains. J Immunol 2004;172:2352-2359.

5 Loos M, Hedderich DM, Friess H, Kleeff J: B7-h3 and its role in antitumor immunity. Clin Dev Immunol 2010;2010:683875.

6 Boorjian SA, Sheinin Y, Crispen PL, Farmer SA, Lohse CM, Kuntz SM, Leibovich BC, Kwon ED, Frank I: T-cell coregulatory molecule expression in urothelial cell carcinoma: clinicopathologic correlations and association with survival. Clin Cancer Res 2008;14:4800-4808.

7 Loos M, Hedderich DM, Ottenhausen M, Giese NA, Laschinger M, Esposito I, Kleeff J, Friess H: Expression of the costimulatory molecule B7-H3 is associated with prolonged survival in human pancreatic cancer. BMC Cancer 2009;9:463.

8 Roth TJ, Sheinin Y, Lohse CM, Kuntz SM, Frigola X, Inman BA, Krambeck AE, McKenney ME, Karnes RJ, Blute ML, Cheville JC, Sebo TJ, Kwon ED: B7-H3 ligand expression by prostate cancer: a novel marker of prognosis and potential target for therapy. Cancer Res 2007;67:7893-7900.

9 Sun J, Chen LJ, Zhang GB, Jiang JT, Zhu M, Tan Y, Wang HT, Lu BF, Zhang XG: Clinical significance and regulation of the costimulatory molecule B7-H3 in human colorectal carcinoma. Cancer Immunol Immunother 2010;59:1163-1171.

10 Zang X, Sullivan PS, Soslow RA, Waitz R, Reuter VE, Wilton A, Thaler HT, Arul M, Slovin SF, Wei J, Spriggs DR, Dupont J, Allison JP: Tumor associated endothelial expression of B7-H3 predicts survival in ovarian carcinomas. Mod Pathol 2010;23:1104-1112.

11 Nygren MK, Tekle C, Ingebrigtsen VA, Fodstad O: B7-H3 and its relevance in cancer; immunological and non-immunological perspectives. Front Biosci (Elite Ed) 2011;3:989-993.

12 Flies DB, Chen L: The new B7s: playing a pivotal role in tumor immunity. J Immunother 2007;30:251-260.

13 Yuan H, Wei X, Zhang G, Li C, Zhang X, Hou J: B7-H3 over expression in prostate cancer promotes tumor cell progression. J Urol 2011;186:1093-1099.

14 Zhao X, Li DC, Zhu XG, Gan WJ, Li Z, Xiong F, Zhang ZX, Zhang GB, Zhang XG, Zhao H: B7-H3 overexpression in pancreatic cancer promotes tumor progression. Int J Mol Med 2013;31:283-291.

15 Stroup DF, Berlin JA, Morton SC, Olkin I, Williamson GD, Rennie D, Moher D, Becker BJ, Sipe TA, Thacker SB: Meta-analysis of observational studies in epidemiology: a proposal for reporting. Meta-analysis Of Observational Studies in Epidemiology (MOOSE) group. JAMA 2000;283:2008-2012.

16 Tierney JF, Stewart LA, Ghersi D, Burdett S, Sydes MR: Practical methods for incorporating summary timeto-event data into meta-analysis. Trials 2007;8:16.

17 Stang A: Critical evaluation of the Newcastle-Ottawa scale for the assessment of the quality of nonrandomized studies in meta-analyses. Eur J Epidemiol 2010;25:603-605.

18 McShane LM, Altman DG, Sauerbrei W, Taube SE, Gion M, Clark GM, Statistics Subcommittee of the NCIEWGoCD: REporting recommendations for tumor MARKer prognostic studies (REMARK). Nat Clin Pract Oncol 2005;2:416-422.

19 Higgins JP, Thompson SG: Quantifying heterogeneity in a meta-analysis. Stat Med 2002;21:1539-1558.

20 Higgins JP, Thompson SG, Deeks JJ, Altman DG: Measuring inconsistency in meta-analyses. BMJ 2003;327:557-560.

21 Egger M, Davey Smith G, Schneider M, Minder C: Bias in meta-analysis detected by a simple, graphical test. BMJ 1997;315:629-634.

22 Boland JM, Kwon ED, Harrington SM, Wampfler JA, Tang H, Yang P, Aubry MC: Tumor B7-H1 and B7-H3 expression in squamous cell carcinoma of the lung. Clin Lung Cancer 2013;14:157-163. 


\section{Cellular Physiology Cell Physiol Biochem 2016;39:1568-1580 and Biochemistry Published online: September 15, 2016 \begin{tabular}{l|l} 
DOI: 10.1159/000447859 2016 The Author(s). Published by S. Karger AG, Basel \\
www.karger.com/cpb
\end{tabular} \\ Ye et al.: B7-H3 and Cancer Survival}

23 Guery T, Roumier C, Berthon C, Renneville A, Preudhomme C, Quesnel B: B7-H3 protein expression in acute myeloid leukemia. Cancer Med 2015;4:1879-1883.

24 Ingebrigtsen VA, Boye K, Tekle C, Nesland JM, Flatmark K, Fodstad O: B7-H3 expression in colorectal cancer: nuclear localization strongly predicts poor outcome in colon cancer. Int J Cancer 2012;131:25282536.

25 Wu CP, Jiang JT, Tan M, Zhu YB, Ji M, Xu KF, Zhao JM, Zhang GB, Zhang XG: Relationship between costimulatory molecule B7-H3 expression and gastric carcinoma histology and prognosis. World J Gastroenterol 2006;12:457-459.

26 Xu H, Chen X, Tao M, Chen K, Chen C, Xu G, Li W, Yuan S, Mao Y: B7-H3 and B7-H4 are independent predictors of a poor prognosis in patients with pancreatic cancer. Oncol Lett 2016;11:1841-1846.

27 Zhang P, Yu S, Li H, Liu C, Li J, Lin W, Gao A, Wang L, Gao W, Sun Y: ILT4 drives B7-H3 expression via PI3K/ AKT/mTOR signalling and ILT4/B7-H3 co-expression correlates with poor prognosis in non-small cell lung cancer. FEBS Lett 2015;589:2248-2256.

28 Arigami T, Uenosono Y, Hirata M, Yanagita S, Ishigami S, Natsugoe S: B7-H3 expression in gastric cancer: a novel molecular blood marker for detecting circulating tumor cells. Cancer Sci 2011;102:1019-1024.

29 Bin Z, Guangbo Z, Yan G, Huan Z, Desheng L, Xueguang Z: Overexpression of B7-H3 in CD133+ colorectal cancer cells is associated with cancer progression and survival in human patients. J Surg Res 2014;188:396-403.

30 Brunner A, Hinterholzer S, Riss P, Heinze G, Brustmann H: Immunoexpression of B7-H3 in endometrial cancer: relation to tumor T-cell infiltration and prognosis. Gynecol Oncol 2012;124:105-111.

31 Chen L, Chen J, Xu B, Wang Q, Zhou W, Zhang G, Sun J, Shi L, Pei H, Wu C, Jiang J: B7-H3 expression associates with tumor invasion and patient's poor survival in human esophageal cancer. Am J Transl Res 2015;7:2646-2660.

32 Chen Y, Sun J, Zhao H, Zhu D, Zhi Q Song S, Zhang L, He S, Kuang Y, Zhang Z, Li D: The coexpression and clinical significance of costimulatory molecules B7-H1, B7-H3, and B7-H4 in human pancreatic cancer. Onco Targets Ther 2014;7:1465-1472.

33 Crispen PL, Sheinin Y, Roth TJ, Lohse CM, Kuntz SM, Frigola X, Thompson RH, Boorjian SA, Dong H, Leibovich BC, Blute ML, Kwon ED: Tumor cell and tumor vasculature expression of B7-H3 predict survival in clear cell renal cell carcinoma. Clin Cancer Res 2008;14:5150-5157.

34 Gregorio A, Corrias MV, Castriconi R, Dondero A, Mosconi M, Gambini C, Moretta A, Moretta L, Bottino C: Small round blue cell tumours: diagnostic and prognostic usefulness of the expression of B7-H3 surface molecule. Histopathology 2008;53:73-80.

35 Hu Y, Lv X, Wu Y, Xu J, Wang L, Chen W, Zhang W, Li J, Zhang S, Qiu H: Expression of costimulatory molecule B7-H3 and its prognostic implications in human acute leukemia. Hematology 2015;20:187-195.

36 Huang C, Zhou L, Chang X, Pang X, Zhang H, Zhang S: B7-H3, B7-H4, Foxp3 and IL-2 expression in cervical cancer: Associations with patient outcome and clinical significance. Oncol Rep 2016;35:2183-2190.

37 Ingebrigtsen VA, Boye K, Nesland JM, Nesbakken A, Flatmark K, Fodstad O: B7-H3 expression in colorectal cancer: associations with clinicopathological parameters and patient outcome. BMC Cancer 2014;14:602.

38 Jin Y, Zhang P, Li J, Zhao J, Liu C, Yang F, Yang D, Gao A, Lin W, Ma X, Sun Y: B7-H3 in combination with regulatory $\mathrm{T}$ cell is associated with tumor progression in primary human non-small cell lung cancer. Int J Clin Exp Pathol 2015;8:13987-13995.

39 Katayama A, Takahara M, Kishibe K, Nagato T, Kunibe I, Katada A, Hayashi T, Harabuchi Y: Expression of B7-H3 in hypopharyngeal squamous cell carcinoma as a predictive indicator for tumor metastasis and prognosis. Int J Oncol 2011;38:1219-1226.

40 Maeda N, Yoshimura K, Yamamoto S, Kuramasu A, Inoue M, Suzuki N, Watanabe Y, Maeda Y, Kamei R, Tsunedomi R, Shindo Y, Inui M, Tamada K, Yoshino S, Hazama S, Oka M: Expression of B7-H3, a potential factor of tumor immune evasion in combination with the number of regulatory $\mathrm{T}$ cells, affects against recurrence-free survival in breast cancer patients. Ann Surg Oncol 2014;21 Suppl 4:S546-554.

41 Mao Y, Li W, Chen K, Xie Y, Liu Q, Yao M, Duan W, Zhou X, Liang R, Tao M: B7-H1 and B7-H3 are independent predictors of poor prognosis in patients with non-small cell lung cancer. Oncotarget 2015;6:3452-3461.

42 Mao Y, Sun J, Wang WP, Zhang XG, Hua D: Clinical significance of costimulatory molecule B7-H3 expression on CD3(+) T cells in colorectal carcinoma. Chin Med J (Engl) 2013;126:3035-3038. 


\section{Cellular Physiology Cell Physiol Biochem 2016;39:1568-1580 and Biochemistry \begin{tabular}{l|l} 
DOI: 10.1159/000447859 & (c) 2016 The Author(s). Published by S. Karger AG, Basel \\
www.karger.com/cpb
\end{tabular} \\ Ye et al.: B7-H3 and Cancer Survival}

43 Sun J, Mao Y, Zhang YQ, Guo YD, Mu CY, Fu FQ Zhang XG: Clinical significance of the induction of macrophage differentiation by the costimulatory molecule B7-H3 in human non-small cell lung cancer. Oncol Lett 2013;6:1253-1260.

44 Sun TW, Gao Q, Qiu SJ, Zhou J, Wang XY, Yi Y, Shi JY, Xu YF, Shi YH, Song K, Xiao YS, Fan J: B7-H3 is expressed in human hepatocellular carcinoma and is associated with tumor aggressiveness and postoperative recurrence. Cancer Immunol Immunother 2012;61:2171-2182.

45 Xu L, Ding X, Tan H, Qian J: Correlation between B7-H3 expression and matrix metalloproteinases 2 expression in pancreatic cancer. Cancer Cell Int 2013;13:81.

46 Xu YH, Zhang GB, Wang JM, Hu HC: B7-H3 and CD133 expression in non-small cell lung cancer and correlation with clinicopathologic factors and prognosis. Saudi Med J 2010;31:980-986.

47 Zang X, Thompson RH, Al-Ahmadie HA, Serio AM, Reuter VE, Eastham JA, Scardino PT, Sharma P, Allison JP: B7-H3 and B7x are highly expressed in human prostate cancer and associated with disease spread and poor outcome. Proc Natl Acad Sci U S A 2007;104:19458-19463.

48 Zhao DD, Lin L, Ge Q, Li ZY, He XP, Xu KL, Lu J, Huang XJ: [Relation of B7-H3 molecule expression in multiple myeloma with poor prognosis and bone destruction]. Zhongguo Shi Yan Xue Ye Xue Za Zhi 2013;21:637-

642.

49 Zhao JM, Wu CP, Wang RC, Xu J, Zhu J, Wei J, Luo GH, Shi LR, Tan M, Tan Y: [Expression and clinical significance of costimulatory molecule B7-H3 mRNA and B7-H3 protein in gastric carcinoma]. Zhonghua Wei Chang Wai Ke Za Zhi 2007;10:458-462.

50 Picarda E, Ohaegbulam KC, Zang X: Molecular Pathways: Targeting B7-H3 (CD276) for Human Cancer Immunotherapy. Clin Cancer Res 2016;10.1158/1078-0432.CCR-15-2428

51 Geng Y, Wang H, Lu C, Li Q, Xu B, Jiang J, Wu C: Expression of costimulatory molecules B7-H1, B7-H4 and Foxp3+ Tregs in gastric cancer and its clinical significance. Int J Clin Oncol 2015;20:273-281.

52 Safaei HR, Rostamzadeh A, Rahmani O, Mohammadi M, Ghaderi O, Yahaghi H, Ahmadi K: Prognostic investigations of B7-H1 and B7-H4 expression levels as independent predictor markers of renal cell carcinoma. Tumour Biol 2016;37:7583-7587.

53 Xu M, Zhang B, Zhang M, Liu Y, Yin FL, Liu X, Zhuo SC: Clinical relevance of expression of B7-H1 and B7-H4 in ovarian cancer. Oncol Lett 2016;11:2815-2819.

54 Chen L, Deng H, Lu M, Xu B, Wang Q Jiang J, Wu C: B7-H1 expression associates with tumor invasion and predicts patient's survival in human esophageal cancer. Int J Clin Exp Pathol 2014;7:6015-6023.

55 Mansfield AS, Roden AC, Peikert T, Sheinin YM, Harrington SM, Krco CJ, Dong H, Kwon ED: B7-H1 expression in malignant pleural mesothelioma is associated with sarcomatoid histology and poor prognosis. J Thorac Oncol 2014;9:1036-1040.

56 Shi J, Qin X, Zhao L, Wang G, Liu C: Human immunodeficiency virus type 1 Tat induces B7-H1 expression via ERK/MAPK signaling pathway. Cell Immunol 2011;271:280-285.

57 Tringler B, Zhuo S, Pilkington G, Torkko KC, Singh M, Lucia MS, Heinz DE, Papkoff J, Shroyer KR: B7-h4 is highly expressed in ductal and lobular breast cancer. Clin Cancer Res 2005;11:1842-1848.

58 Wang W, Xu C, Wang Y, Yu L, Zhang X: Prognostic values of B7-H4 in non-small cell lung cancer. Biomarkers 2016;10.1080/1354750X.2016.12039971-16.

59 Tringler B, Liu W, Corral L, Torkko KC, Enomoto T, Davidson S, Lucia MS, Heinz DE, Papkoff J, Shroyer KR: B7-H4 overexpression in ovarian tumors. Gynecol Oncol 2006;100:44-52.

60 Krambeck AE, Thompson RH, Dong H, Lohse CM, Park ES, Kuntz SM, Leibovich BC, Blute ML, Cheville JC, Kwon ED: B7-H4 expression in renal cell carcinoma and tumor vasculature: associations with cancer progression and survival. Proc Natl Acad Sci U S A 2006;103:10391-10396.

61 Wu L, Deng WW, Yu GT, Mao L, Bu LL, Ma SR, Liu B, Zhang WF, Sun ZJ: B7-H4 expression indicates poor prognosis of oral squamous cell carcinoma. Cancer Immunol Immunother 2016;10.1007/s00262-0161867-9

62 Zhao X, Guo F, Li Z, Jiang P, Deng X, Tian F, Li X, Wang S: Aberrant expression of B7-H4 correlates with poor prognosis and suppresses tumor-infiltration of CD8+ T lymphocytes in human cholangiocarcinoma. Oncol Rep 2016;36:419-427.

63 Zhang SA, Wu ZX, Zhang X, Zeng ZY, Li DL: Circulating B7-H4 in serum predicts prognosis in patients with hepatocellular carcinoma. Genet Mol Res 2015;14:13041-13048.

64 Wang L, Cao NN, Wang S, Man HW, Li PF, Shan BE: Roles of coinhibitory molecules B7-H3 and B7-H4 in esophageal squamous cell carcinoma. Tumour Biol 2016;37:2961-2971. 